\title{
An update on cyclodextrins as drug vehicles for antimicrobial applications
}

\author{
Ece Özcan Bülbül ${ }^{1}$, Kalliopi Eleftheriadou ${ }^{2}$, Neslihan Üstündağ Okur ${ }^{3}$, Panoraia I. Siafaka ${ }^{4}$ \\ ${ }^{1}$ Department of Pharmaceutical Technology, Faculty of Pharmacy, İstanbul University, İstanbul, Turkey \\ ${ }^{2}$ School of Pharmacy, Faculty of Health Sciences, Aristotle University of Thessaloniki, Thessaloniki, Greece \\ ${ }^{3}$ Department of Pharmaceutical Technology, Faculty of Pharmacy, University of Health Sciences, İstanbul, Turkey \\ ${ }^{4}$ School of Chemistry, Faculty of Sciences, Aristotle University of Thessaloniki, Thessaloniki, Greece
}

\begin{tabular}{l}
\hline A R T I C L E I N F O \\
\hline Article history: \\
Received $\quad$ 16 May 2020 \\
Revised $\quad$ 22 May 2020 \\
Accepted $\quad$ 29 May 2020 \\
Online $\quad$ 01 Jun 2020 \\
Published $\quad$ 15 Jun 2020 \\
Keywords: \\
Antibacterial \\
Antifungal \\
Cyclodextrins \\
Inclusion complexes \\
Solid dispersions \\
*Corresponding author: \\
neslihanustundag@yahoo.com \\
\hline
\end{tabular}

\begin{abstract}
A B S T R A C T
Cyclodextrins belong to cyclic oligosaccharides comprised of $\alpha-(1,4)$ linked glucopyranose groups. Their interesting supramolecular cavity-like structure can host active molecules providing a breeding ground for drug delivery systems. Cyclodextrins, due to their unique functional structure, can produce host-guest complexes with active ingredients, such as drugs, peptides, proteins, etc.; the complexes resulted from intramolecular interactions leading to stable molecules vehicles. Moreover, cyclodextrins are already applied in pharmaceutical industry applications since they can induce the solubility of lipophilic compounds and provide bioavailability and excellent safety profile and stability. In this review, the basic background for cyclodextrins and their current applications in the antimicrobial field are discussed. Besides, the antibacterial and antifungal-applications in the pharmaceutical field attract most researchers because of microbes' resistance. Regarding this, the most recent cyclodextrin inclusion complexes with antimicrobial and antifungal drugs are summarized in this article.
\end{abstract}

This is an open-access article licensed under the Creative Commons Attribution 4.0 International License (CC-BY). (cc) BY

\section{INTRODUCTION}

Over the last decades, solid dispersion (SD) technology has been utilized to improve oral bioavailability via the enhancement of poorly soluble drug solubility $[1,2]$. Besides, given that most of the active molecules are lipophilic with low aqueous solubility, their delivery in the form of amorphous SDs seems to be advantageous [3]. Except for oral bioavailability, SDs have also been applied for maximizing ocular bioavailability, as well [4]. SDs have been defined as the systems were one or more active molecules are dispersed in an inert carrier produced by various methods, melting, dissolution, or combination of them and others [5]. Solvent evaporation, electrospinning, spray drying, and hot melting, cyclodextrin complexation, as well as kneading [6-10], are commonly used techniques. Cyclodextrin (CD) complexes belong to the most handful of SDs categories $[2,11]$.

\section{CYCLODEXTRINS}

CDs belong to the family of cyclic oligosaccharides comprised of glucopyranose units. Other names of CDs are Schardinger sugars or cycloamylose dextrins. Vielliers in 1891 was the first who discovered CDs which at that time were named as "cellulosing" [12]. Some years later, Schardinger, who has been considered as the "founding father" of CD chemistry, describes the preparation and separation methods of CDs. In contrast, recently, Loftsson and coworkers have significantly contributed to the development of the $\mathrm{CD}$ field [13-17].

The most common CDs are $\alpha, \beta$, and $\gamma$, constituted by 6 , 7 , and 8 glucopyranose units (Figure 1), respectively. However, except for them, $\delta$-, $\zeta-, \xi$ - and even $\eta$-CD (9-12 units) have been confirmed. Their structure mimics doughnut ring exists as a truncated cone (Figure 2); the outer part of the cone presents hydrophilic nature resulted from the hydroxyl groups of the glucopyranose units while the inner cavity is apolar. The truncated shape is the result of the rotation of the primary hydroxyl groups located at the end of the cavity reducing the size of the cavity toward the side of the secondary hydroxyls regarding the $\mathrm{C} 2$ and $\mathrm{C} 3$ carbon atoms of the glucose units located to the edges of the cavity [18]. The main property of CDs is their ability to form hostguest complexes leading to stable complexes; one or two guest molecules can be entrapped by one, two, or three CDs. The formation of the complexes can be easily detected by phase solubility studies $[2,19]$. It is generally accepted that 
the complex formation issued by various mechanisms [20] such as;

a. van der Waals interactions between the CD cavity and the hydrophobic unit of the guest molecules [21],

$\boldsymbol{b}$. hydrogen bonding between the polar functional groups of the guest molecules and the hydroxyl groups of the CD [21],

c. release of high energy water molecules from the cavity during the complexation

$d$. release of strain energy into the ring structure system of the $\mathrm{CD}[22]$.

Also, CDs due to the presence of the hydroxyl groups can be easily functionalized, providing derivatives such as hydroxypropyl- $\beta-C D$, sulfobutylether- $\beta-C D$ [23], and others. These derivatives present more excellent solubility in water or improved properties. Asides from these, CDs can be used to graft polymers resulting in multifunctional drug carriers [24].
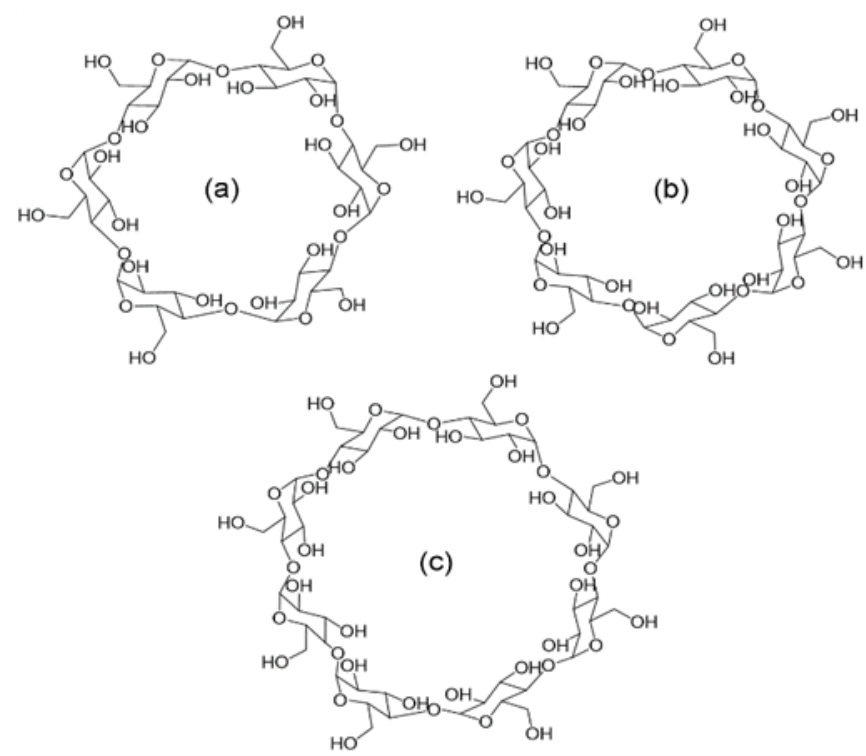

Figure 1. The most common cyclodextrins structures (a) $\alpha-C D$, (b) $\beta-C D$ and (c) $\gamma-C D$

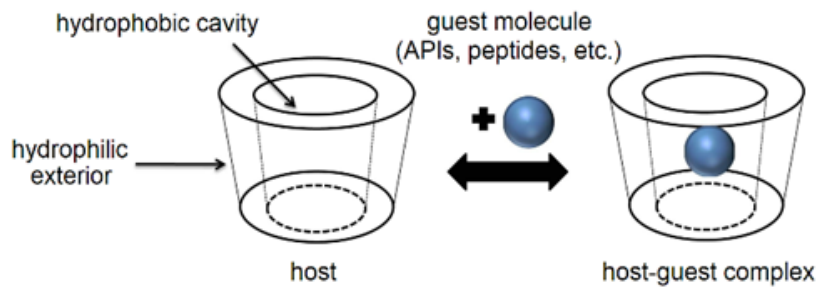

Figure 2. Cyclodextrin structure and complexation mechanism (host-guest complex) APIs = Active pharmaceutical ingredients

The natural CDs $(\alpha-, \beta-, \gamma-)$ are not toxic but present limited water solubility [25]. Table 1 summarizes basic properties of natural CDs. This limitation can be overcome via their functionalization with;

a. propylene oxide leading to hydroxypropylated CDs,

b. monochloroacetic acid resulting in carboxymethylated CDs

c. methyl iodide methylated CDs and

d. 4-butane sultone resulting in sulfobutylether CDs [26].
Table 1. Physicochemical properties of $\alpha-, \beta-, \gamma-C D s$

\begin{tabular}{lccc}
\hline Properties & $\boldsymbol{\alpha}-\mathbf{C D}$ & $\boldsymbol{\beta}$-CD & $\boldsymbol{\gamma}$ - CD \\
\hline Glucose units & 6 & 7 & 8 \\
Cavity diameter $(\AA)$ & $4.7-5.3$ & $6.0-6.5$ & $7.0-8.3$ \\
Cavity height $(\AA)$ & 7.9 & 7.9 & 7.9 \\
Cavity volume $(\AA)$ & 174 & 262 & 427 \\
$\mathrm{Crystal}$ & hexagonal & monocyclic par- & quadratic \\
$\operatorname{logP}_{\text {oct/water }}{ }^{2}$ & lattice & allelograms & prism \\
$\mathrm{MW}^{2}(\mathrm{~g} / \mathrm{mol})$ & -13 & -14 & -17 \\
$\mathrm{~F}_{\text {oral }}{ }^{3}$ & 973 & 1135 & 1297 \\
\multicolumn{2}{c}{${ }^{1}$ logarithm of the calculated octanol/water partition coefficient } \\
${ }^{2}$ molecular weight \\
${ }^{3}$ fraction of the absorbed CD amount when orally administered to rats
\end{tabular}

\subsection{Preparation and Characterization Methods}

For the preparation of $\mathrm{CD}$ complexes with various active ingredients, several preparation methods have been proposed through literature. Commonly used methods are freezedrying, physical mixing, kneading, co-precipitation, solvent evaporation, and supercritical process [27-31]. The developed complexes to be characterized, are analyzed using Fourier-Transformed Spectroscopy (FTIR), Differential Scanning Calorimetry (DSC), scanning electron microscopy (SEM), and x-ray diffractometry (XRD) [2]. In further, the successful complexation is examined via various physicochemical methods. In detail, numerous spectroscopic methods as fluorescence spectroscopy, Ultra-violet/visible spectroscopy aqueous phase solubility studies, and nuclear magnetic resonance (NMR) spectroscopy are reported to detect the complexation between drug and CDs [32-34].

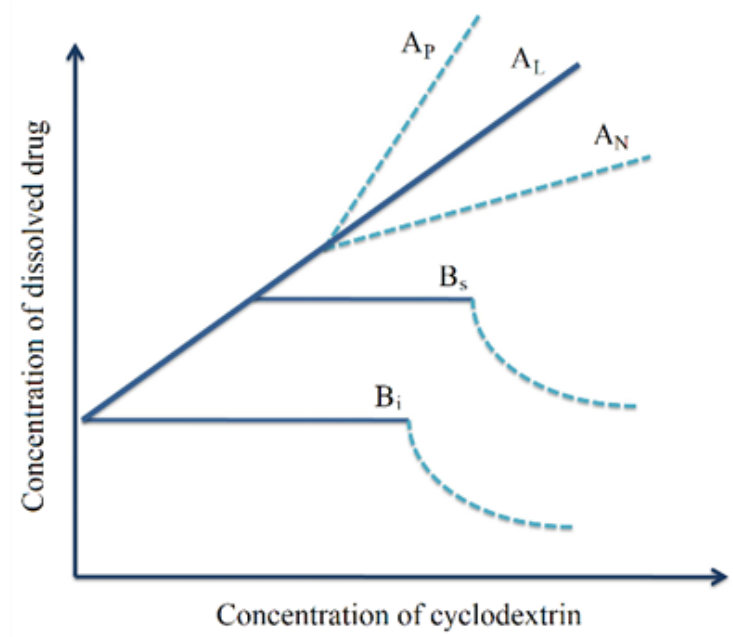

Figure 3. Phase-solubility profiles acquired through Higuchi and Connors methods [33].

The phase solubility studies, according to the molecule solubility in moles/L plotted against the molar $\mathrm{CD}$ concentration, is one of the most common and easy methods utilized. Although these studies do not prove the formation of the inclusion complexes, describe how the increment of $\mathrm{CD}$ concentration affects drug solubility. Five main profiles have been identified (Figure 3). Generally, A-type profiles are acquired from water-soluble $\mathrm{CD}$ derivatives (i.e., HP- $\beta$ CD) while B-type from natural CDs. First, A-type phase (AL, AP, AN) solubility profiles are obtained when drug solubility of the drug-enhanced by enhancing $\mathrm{CD}$ 
concentration through the complexation between the hydrophilic drug and $\mathrm{CD}$. AL profile is acquired when the complex is first-order regarding $\mathrm{CD}$ and first or higher-order in respect of the drug resulting in $1: 1,2: 1$, or $3: 1 \mathrm{drug} / \mathrm{CD}$ complexes. AP profile identifies the complexes with the first order of drug, but a second or higher order of CD. AN profile is difficult to be examined, but the variance from linearity could be associated with various changes, according to Jansook et al. [26]. The B-type profiles specify the formation of complexes with low solubility in the water media [17].

\section{CYCLODEXTRIN BASED ANTIMICROBIAL SYSTEMS}

Currently, physicians and researchers from the health sciences field are quite aware of the antimicrobial resistance; the ability of microbes to resist the effects of medications [35]. Both microbe and fungi resistance represents a major clinical challenge to clinicians since they can resist certain medications leading to severe complications of the patients' life [35-37]. Thus, this research field based on antimicrobial systems is a developing one. The researchers either focus on new active ingredients or other administration routes. Besides, most of the antimicrobial ingredients are lipophilic, limiting their oral use. Except, oral administration, the ocular and parenteral routes are widely utilized for the delivery of antimicrobial drugs. Consequently, the use of CDs as a matrix for the delivery of such drugs could be very promising. There are several marketed products based on CD complexes and various active ingredients. In 1976, the first marketed product was developed via prostaglandin E2 and $\beta-C D$ in the form of sublingual tablets [19]. More specifically, in the case of antimicrobial pharmaceutical field, a known marketed product is the intravenous solution of Voriconazole (VRC) and Sulfobutylether- $\beta$-CD complex, supplied by Pfizer under the brand name $\mathrm{Vfend}^{\circledR}$.

\subsection{Cyclodextrins-Antibacterial Drug Complexes}

An oral drug formulation based on tebipenem pivoxyl (TP) has been proposed. Tebipenem pivoxil- $\beta$-cyclodextrin (TP- $\beta$-CD) complex was prepared, and the physicochemical properties were changed. The inclusion of TP- $\beta-C D$ was confirmed using DSC (thermal method) as well as infrared and Raman spectroscopy (spectral method). Due to the inclusion complexation, there has been an increase in solubility and chemical solid-stability. Biologically primary effects of TP and $\beta-C D$ interactions decreased TP permeability through Caco-2 cell using efflux effect inhibition and enhanced antibacterial activity. The pharmaceutical formulation showed a great opportunity for the treatment of resistant bacterial infections [38].

The formation of the $\beta-\mathrm{CD}$ inclusion complex with levofloxacin was studied using fluorescence spectroscopy in $\mathrm{pH} 7.4$ buffer solution. It was revealed that a $1: 1$ inclusion complex of $\beta-C D$ with levofloxacin was developed, as the ${ }^{1} \mathrm{H}$ NMR and IR methods depicted. The complex formation between levofloxacin and gadolinium (III) ion was examined in aqueous solutions with and without $\beta-\mathrm{CD}$. The stability and stoichiometry constants of the complexes were reported, and the concentration distribution of some complexes has been measured as a function of $\mathrm{pH}$. The effect of $\beta-\mathrm{CD}$ on dissociation constants, $\mathrm{Ka}$ of levofloxacin, and stability constants of levofloxacin-gadolinium (III) complexes were checked. Also, gadolinium (III) distribution in human blood was showed with computer simulation [39].

The main complication of hernia repair is mesh-infection. Bacterial infections can develop in textile structures, after knitted mesh implantation. Sanbhal et al. prepared polypropylene (PP) mesh materials, which were modified with $\beta-C D$ and hexamethylene diisocyanate and then loaded with levofloxacin for the treatment of hernia mesh-infection. First, oxygen plasma was able to provide surface roughness, and then hexamethylene diisocyanate was suitably grafted onto surfaces of PP fibers. Afterward, the CD was grafted onto the hexamethylene diisocyanate modified polypropylene meshes, and levofloxacin HCL loaded into the CD. A sustained drug release was obtained between surfaces of aqueous environment and meshes. In further, samples showed sustained antibacterial activities against both Gram-positive and negative bacteria for 10 and 7 days, respectively. The complexes demonstrated a burst release after 6 hours, followed by a sustained release for 48 hours. The modified mesh was the most stable between all specimens and provided more sustained drug release, which is essential for future clinical treatments [40].

Aytaç et al. modified pharmaceutical-grade CDs (HP- $\beta$ $\mathrm{CD}, \mathrm{M}-\beta-\mathrm{CD}$, and HP- $\gamma-\mathrm{CD})$ were used for complexation with linalool. These CDs were acquired due to their higher solubility in comparison with natural CDs. Their higher water solubility could induce their successful electrospinning to nanofibrous structures. They prepared nanofibers based on the $\mathrm{CD}$ /linalool-inclusion complex using an electrospinning apparatus. The high mass of linalool (45-89\%) was loaded into the nanofibers because of CD complexation. Besides, the thermal stability of linalool increased due to the $\mathrm{CD}$ inclusion complexation. The complexes demonstrated very high antibacterial activity against Gram-positive ( $S$. aureus) and Gram -negative (E. coli) bacteria. CD complexes were dissolved entirely in water in two seconds. The produced CD based nanofibers confer high linalool loading capacity, the effective antibacterial activity of linalool, and enhanced shelf life [41].

Szabó et al. studied moxifloxacin (MOX) and $\beta-\mathrm{CD}$ complexation to enhance its antibacterial property. This inclusion complexation was examined with NMR, mass spectrometry, affinity capillary electrophoresis, DSC, and FTIR techniques. The antimicrobial test showed that the MOX inclusion complex offers slightly improved activity against Enterococcus faecalis and Methicillin-resistant Staphylococcus aureus (MRSA) [42].

Masood et al. prepared roxithromycin (ROX) encapsulated in the cavity of $\beta-C D$ and $H P-\beta-C D$ formulations, to enhance ROX poor solubility. In further, blank and ROX loaded poly (lactic-co-glycolic acid) nanoparticles were prepared. The nanoparticles were capable of inhibiting the growth of multidrug-resistant Gramnegative and Gram-positive bacteria compared to the HP- $\beta$ CD-ROX/PLGA NPs and $\beta$-CD-ROX/PLGA NPs [43].

He et al. produced rifampicin (RFP) HP- $\beta-C D$ complexes to form a molecular inclusion complex (MRICD) with excellent stability and solubility. The complex was prepared using a solid-state grinding technique without any water revealing a greater dissolution rate of than free RFP. 
Moreover, the complex showed enhanced antibacterial activity and improved the physical properties of RFP [44].

Choi et al. investigated the complexation effect of mono6-deoxy-6-aminoethylamino- $\beta$-cyclodextrin (Et- $\beta$-CD) on the bioavailability and solubility of ciprofloxacin which is used to treat bacterial infections. The complexes were characterized using DSC, FE-SEM, FT-IR, T1 relaxation, DOSY NMR spectroscopy, 2D NOESY, and molecular modeling tests. The solubility of the ciprofloxacin complex was improved by seven-time when compared to pure ciprofloxacin. The antibacterial activity of the ciprofloxacin complex against Staphylococcus aureus was increased, demonstrating growth inhibition. The results of this study suggested that the induced oval-shaped cavity of Et- $\beta-C D$ may be used for other guest molecules besides ciprofloxacin [45].

Taha et al. aimed to load antibiotics onto hip implants for preventing infection risk after a total hip replacement. They modified the surface of hydroxyapatite (HA) coated titanium implant material (Ti-HA) with poly $\mathrm{CD}$ for loading tobramycin and rifampicin. They achieved a sustained drug delivery. A strong efficacy against both Enterobacter cloacae and Staphylococcus aureus was achieved because of dualantibiotic loading. The antibacterial coating (polyBTCA/ Me- $\beta-C D$ ) for an HA-coated titanium prosthesis provided an enlarged therapeutic spectrum [46].

\subsection{Cyclodextrins-Antifungal Drug Complexes}

Li et al. prepared fluconazole (HFlu) loaded inclusion complexes with $\beta-\mathrm{CD}$ and HP- $\beta-\mathrm{CD}$ via the co-precipitation technique. The 1:1 stoichiometry for both $\mathrm{CD}$ complexes was achieved according to phase solubility and fluorometric studies. These preparations were characterized by DSC-TGA and ESI-MS spectra analyses. Finally, Flu-HP- $\beta-C D$ showed higher stability than for HFlu- $\beta-C D$ [47].

Orgován et al. aimed to quantify acid-base and CDcomplex formation equilibria of fluconazole. ${ }^{1} \mathrm{H}-\mathrm{NMR} \mathrm{pH}$ titrations exhibited protonation levels in the acidic and the highly basic region $(\log K 1=11.96)$. The structure and stability of its complexes with $\beta$-CD (2-hydroxy) propyl- $\beta-C D$ and sulfobutyl ether- $\beta-C D$ were studied by NMR methodologies. The CD complexes of fluconazole are of average stability. Two isomeric complexes of comparable stability were formed between the $\beta-\mathrm{CD}$ and fluconazole [48].

Oral VRC is used for patients with kidney failure due to concerns about CD accumulation. Siafaka et al. compared two different preparation methods for the improvement of the dissolution rate of VRC. Poly( $\varepsilon$-caprolactone) (PCL) electrospun fibers were developed with an electrospinning process, and $\beta-\mathrm{CD}$ complexes were prepared with an inclusion complexation method. The formulations were loaded with various concentrations of VRC. PCL nanofibers were characterized based on morphology. $\beta$-CD complexes were evaluated for phase solubility. An improved VRC solubility was found for all formulations, whereas inhibition of fungi proliferation was also revealed [2]. Kim et al. studied the effects of IV VRC formulated using sulfobutylether $\beta$-cyclodextrin (SBECD) in patients with kidney failure. An observational study was conducted on 25 adult invasive aspergillosis patients treated with IV VRC. Even in patients with renal insufficiency after VRC treatment, no significant impairment of kidney function was observed in any patient. IV VRC formulated with SBECD did not cause an increase in the incidence of serious adverse events, including nephrotoxicity in hematological patients with $\mathrm{CrCl}<50 \mathrm{~mL} / \mathrm{min}$ [49]. According to another study, VRC was incorporated in SBECD for renal function. The impact of long-term use of intravenous VRC on renal function is indefinite. Their retrospective study of data proved that the worsening of renal function was notably connected with a total dose of IV VRC $(\geq 400 \mathrm{mg} / \mathrm{kg})$, recommending that a higher cumulative dosage of IV VRC is a risk factor for renal dysfunction [50].

Sun et al. used the electrospinning technique to prepare VRC incorporated polyvinyl alcohol (PVA)/HP- $\beta-C D$ blended nanofibers for ocular application. HP- $\beta-C D$ content increased drug solubility. The nanofibers presented beadfree mean fiber diameters of $307 \pm 31 \mathrm{~nm}$, and VRC was released in a sustained profile. The proton nuclear magnetic resonance was practiced to analyze the molar proportion of HP- $\beta$-CD/VRC in the nanofibers. The nanofibers remarkably improved the bioavailability and increased the half-life of VRC in rabbit tears when compared with a VRC solution. VRC nanofibers were found promising for ophthalmic drug delivery [51]. Vass et al. conducted a study to evaluate electrospinning as an alternative process of the dilution injection dosage form. High-speed electrospinning with a new continuous cyclone collection was applied to produce a formulation of VRC using sulfobutylether- $\beta$-cyclodextrin (SBE- $\beta-C D)$. SBE- $\beta-C D$ worked as a 'quasi-polymer,' and it could be electrospun despite its low molecular weight. The crystalline form of VRC in fibers was not detected according to DSC and XRD methods. Also, it was determined by energy dispersive spectroscopy and Raman mapping measurements that the VRC in the amorphous form in the fibers showed a proper distribution. According to Reconstitution tests with ground fiber powder, a clear solution formed later 30 seconds (similar to $\mathrm{Vfend}^{\circledR}$ ). With this study, it has been proved that aqueous high-speed electrospinning, is an economically viable manufacture alternative compared to freeze-drying [52].

Herrera et al. used a co-precipitation method for preparation inclusion complexes based on $\beta-C D$ and antimicrobial drugs. These preparations were characterized by entrapment efficiency (EE), thermal analysis, X-ray diffraction, 1H NMR spectroscopy, and water sorption. They also evaluated for drug release and antifungal activity. EE\% was found between 66-91\%. High relative humidity was affected by drug release. These complexes also showed antifungal activity on $B$. cinereal. For this reason, these preparations could be used in antifungal packaging [53].

Econazole nitrate $(\mathrm{ECN})$ is a weakly basic drug with low water solubility resulting in low bioavailability. The ECN/ CD complex was used to increase the solubility of the drug in the aqueous medium. Jansook et al. conducted a study to determine the effect of $\mathrm{CD}$ inclusion complex and $\mathrm{pH}$ adjustment on ECN solubility. The solubility of this drug in acidic solutions containing $\alpha-\mathrm{CD}$ was higher under the same conditions than aqueous $\gamma$-CD solutions. The presence of the ECN/CD complex was confirmed using proton nuclear magnetic resonance spectroscopy. Autoclaving increased the 
drug stability of ECN/CD complexes. To create nanoparticles and microparticles, $\gamma$-CD complexes can self-assembled, while $\alpha-C D$ complexes are at a negligible level of selfassembly. ECN $/ \alpha-C D$ has been shown to increase antifungal activity against filamentous fungi [54].

Eleamen et al. used a freeze-drying method for preparing a complex of HP- $\beta-\mathrm{CD}$ and $6 \mathrm{CN} 10$ (a poorly water-soluble 2-aminothiophene derivative). The complexes were characterized by infrared/Raman spectroscopy, thermal analysis, scanning electron microscopy, and X-ray diffraction. The water solubility of $6 \mathrm{CN} 10$ with HP- $\beta-\mathrm{CD}$ improved more than 29 times. The antifungal activity against Cryptococcus neoformans presented the better performance of the complex (46.66 $\mu \mathrm{g} / \mathrm{mL})$ compared to the free drug (166.66-333.33 $\mu \mathrm{g} /$ $\mathrm{mL})$. This study provided useful complexation with low soluble compounds and HP- $\beta-\mathrm{CD}[55]$.

Gontijo et al. produced CDs with ellagic acid. Caco- 2 cell lines cultivated in a Transwell ${ }^{\circledR}$ insert were contaminated with Candida albicans to promote an in vitro model. Characterization studies of complexes and microbial effects were evaluated. Ellagic acid exhibited the ability to defeat the Candida albicans invasion. Poor absorption and poor water solubility of ellagic acid probably limited this ability. Ellagic acid/hydroxypropyl- $\beta-C D$ did not improve the antifungal activity. Poor water solubility was improved with HP- $\beta$-CD complexation. This formulation presented a promising antifungal activity [56].

Propiconazole nitrate incorporated inclusion complexes prepared by the freeze-drying method. The preparations were characterized by $1 \mathrm{H}-\mathrm{NMR}, 2 \mathrm{D}$ Roesy NMR, and DSC. The complexes with sulfobutylether- $\beta-C D$ had the highest association constant values, and the inclusion efficiency was close to $100 \%$. Antifungal activity, in silico docking and molecular dynamics simulations, were evaluated. For all complexes showed similar results on Candida spp. The complexes were also evaluated for cytotoxicity, and the $\beta$-CD complex was showed higher cytotoxicity than other complexes [57].

Teodoro et al. were prepared gallic acid CDs (GA/HP- $\beta$ CD) by spray drying to enhance gallic acid (GA) solubility for the management of Candida albicans biofilm. Complexes were characterized by drug loading, SEM, and DSC and were tested on Candida albicans biofilm. The drug loading $\%$ was found approximately $10 \%$. Inclusion complexes were confirmed with SEM and DSC tests. The developed complex kept the antimicrobial activity of the pure GA while it was found effective on Candida albicans biofilms of 24 and $48 \mathrm{~h}$. Besides, the in vivo results showed an anti-inflammatory activity of GA/HP- $\beta-\mathrm{CD}[58]$.

\section{CURRENT STATUS OF CYCLODEXTRIN COMPLEXES IN PHARMACEUTICAL APPLICATIONS}

CD complexes included in about 40 marketed pharmaceutical applications worldwide, in addition to many foods, toiletry, and cosmetic products [59]. CD complexes are all found in one or more pharmaceutical products in Japan, the USA, or Europe: Cefotiam hexetil hydrochloride (Pansporin T, Japan), Benexate hydrochloride (Ulgut, Lonmiel, Japan), Omeprazole (Omebeta, Europe), Piroxicam
(Brexin, Europe), Cisapride (Propulsid, Europe), Itraconazole (Sporanox, Europe, USA), Mitomycin (Mitozytres, USA), 17b -Estradiol (Aerodiol, Europe), Voriconazole (Vfend, Europe, USA), Ziprasidone maleate (Geodon, Zeldox, Europe, USA), Diclofenac sodium (Voltaren, Europe) [60].

The biopharmaceutical classification system (BCS) divides oral drugs into 4 cases based on their solubility and gastrointestinal permeability. CD complexes mostly studied to improve oral bioavailability of Class II drugs (poor aqueous solubility - good permeability) and Class IV drugs (poor aqueous solubility - poor permeability) [59]. The complexes of these drugs with CDs could mask undesirable properties. CD carriers such as nanosystems (nanosponges, nanofibers, dendrimers, metallic nanoparticles, quantum dots, nanoemulsions), liposomes, micelles, micro rods, niosomes, and siRNA may hide the undesired characteristics of drugs, thus improving their bioavailability $[61,62]$.

$\mathrm{CD}$ has been extensively applied in gene therapy, nanomedicine therapy, cell therapy, chemotherapy, and immunotherapy. Studies have shown that numerous anticancer drugs, with properties such as instability, lack of physicochemical properties, or poor water solubility, have limited application in pharmaceutical applications [62]. Also, $\alpha-C D$ and $\beta-C D$ are not degraded by pancreatic amylases enzymes and human salivary. Thus, CD-drug complexes remain unspoiled in the upper GI tract until they reach the colon. In this state, CD complexes of anti-cancer drugs serve as a hopeful system by improving both solubility and the availability of anti-cancer drugs at the colon site [63]. Also, the versatile nature of $\mathrm{CDs}$ may be used to defeat the limitations of ophthalmic topical delivery systems. CDs provide an attractive way to increase the solubility of wettable and poorly soluble drugs, to enhance their permeability and retention on ocular surfaces. $C D$ has the potential to develop conventional eye drops to offer more excellent permeability, safety, effectiveness, and stability in the topical ocular delivery of the posterior and anterior segments [64]. A review has presented regarding applications of CDs in medical textiles. It was about the release/ deposition of the drug onto/from a textile underlayer to the dermis, with CD complexes. Therapeutic textile fabrics with controlled drug release give an alternative with great medical potential, given both their numerous biopharmacological advantages. The use of CD-based medical textile fabrics applies to antimicrobial, anti-psoriasis, antiallergic (atopic and contact dermatitis), or venous insufficiency at the level of the dermis [65].

\section{CONCLUSION}

In this review, an update on CDs as drug vehicles for antimicrobial applications was presented. Overall, CDs as drug vehicles promote a promising approach for antimicrobial applications due to its ability to increase stability and the water solubility of antimicrobial drugs by inclusion complexation. Antimicrobial tests in some studies have shown that the inclusion complex offers more improved activity than pure drugs. In conclusion, research over the past few years has led to the development of $\mathrm{CD}$ as an antimicrobial drug carrier material. The antimicrobial drug/ CD complexes may have many advantages over the conventional antimicrobial drug delivery systems. Further 
technological and research advancements are expected to widen the importance of CDs in antimicrobial applications.

\section{AUTHOR CONTRIBUTIONS}

Concept: EÖB, KE, NÜO, PIS; Design: EÖB, KE, NÜO, PIS; Supervision: NÜO, PIS; Materials: EÖB, KE, NÜO, PIS; Data Collection and/or Processing: EÖB, KE, NÜO, PIS; Analysis and/or Interpretation: EÖB, KE, NÜO, PIS; Literature Search: EÖB, KE, NÜO, PIS; Writing: EÖB, KE, NÜO, PIS; Critical Reviews: NÜO, PIS.

\section{ACKNOWLEDGMENTS}

None.

\section{CONFLICT OF INTEREST DECLARATION}

The authors declare no conflict of interest.

\section{REFERENCES}

[1] Cid AG, Simonazzi A, Palma SD, Bermúdez JM. Solid dispersion technology as a strategy to improve the bioavailability of poorly soluble drugs. Ther Deliv. (2019); 10: 363-382. https://doi.org/10.4155/tde-2019-0007

[2] Siafaka P, Üstündağ Okur N, Mone M, Giannakopoulou S, Er S, Pavlidou E, Karavas E, Bikiaris D. Two different approaches for oral administration of voriconazole loaded formulations: electrospun fibers versus $\beta$-cyclodextrin complexes. Int J Mol Sci. (2016) 17(3): 282 .

https://doi.org/10.3390/ijms17030282

[3] Schittny A, Huwyler J, Puchkov M. Mechanisms of increased bioavailability through amorphous solid dispersions: a review. Drug Deliv. (2020); 27(1): 110-127.

https://doi.org/10.1080/10717544.2019.1704940

[4] Nabekura T, Ito Y, Cai H, Terao M, Hori R. Preparation and in vivo ocular absorption studies of disulfiram solid dispersion. Biol Pharm Bull. (2000); 23(5): 616-620. https://doi.org/10.1248/bpb.23.616

[5] Karagianni A, Kachrimanis K, Nikolakakis I, Co-Amorphous solid dispersions for solubility and absorption improvement of drugs: composition, preparation, characterization and formulations for oral delivery. Pharmaceutics. (2018); 10(3): 98. https://doi.org/10.3390/pharmaceutics10030098

[6] Üstündağ Okur N, Filippousi M, Okur ME, Ayla Ş, Çağlar EŞ, Yoltaş A, Siafaka PI. A novel approach for skin infections: controlled release topical mats of poly(lactic acid)/poly(ethylene succinate) blends containing Voriconazole. J Drug Deliv Sci Technol. (2018); 46: 74 86. https://doi.org/10.1016/j.jddst.2018.05.005

[7] Özcan Bülbül E, Mesut B, Cevher E, Öztaş E, Özsoy Y. Product transfer from lab-scale to pilot-scale of quetiapine fumarate orodispersible films using quality by design approach. $J$ Drug Deliv Sci Technol. (2019); 54: 101358. https://doi.org/10.1016/j.jddst.2019.101358

[8] Siafaka PI, Barmbalexis P, Bikiaris DN, Novel electrospun nanofibrous matrices prepared from poly(lactic acid)/poly(butylene adipate) blends for controlled release formulations of an antirheumatoid agent. Eur J Pharm Sci. (2016); 88: 12-25.

https://doi.org/10.1016/j.ejps.2016.03.021

[9] Mahmah O, Tabbakh R, Kelly A, Paradkar A. A comparative study of the effect of spray drying and hot-melt extrusion on the properties of amorphous solid dispersions containing felodipine. $J$ Pharm Pharmacol. (2014); 66(2): 275-284

https://doi.org/10.1111/jphp.12099

[10] Dhillon B, Goyal NK, Sharma PK. Formulation and evaluation of glibenclamide solid dispersion using different methods. Glob $J$ Pharmacol. (2014); 8(4): 551-556. https://doi.org/10.5829/idosi.gjp.2014.8.4.84283

[11] Pilli R, Nagabhushanam M, Kadali SDVSK. Etodolac dissolution improvement by preparation of solid dispersions. Int J Pharm Sci Res. (2014); 5(11): 4774-4791. https://doi.org/10.13040/IJPSR.0975-8232.5(11).4774-91

[12] Szente L, Szemán J, Sohajda T. Analytical characterization of cyclodextrins: History, official methods and recommended new techniques, J Pharm Biomed Anal. (2016); 130: 347-365. https://doi.org/10.1016/j.jpba.2016.05.009

[13] Jin ZY, Cyclodextrin chemistry, Beijing: World Scientific Publishing Company / Chemical Industry Press; (2013) 292p. ISBN:978-981-4436-79-3
[14] Kurkov SV, Loftsson T. Cyclodextrins. Int J Pharm. (2013); 453(1): 167-180.

https://doi.org/10.1016/j.ijpharm.2012.06.055

15] Loftsson T, Brewster ME. Pharmaceutical applications of cyclodextrins. 1. Drug solubilization and stabilization. J Pharm Sci. (1996); 85(10): 1017-1025. https://doi.org/10.1021/js950534b

[16] Loftsson T, Duchene D. Cyclodextrins and their pharmaceutical applications. Int J Pharm. (2007); 329(1-2): 1-11. https://doi.org/10.1016/j.ijpharm.2006.10.044

[17] Loftsson T, Hreinsdóttir D, Másson M. Evaluation of cyclodextrin solubilization of drugs. Int J Pharm. (2005); 302(1-2): 18-28. https://doi.org/10.1016/j.ijpharm.2005.05.042

[18] Martin J, Díaz-Montaña EJ, Asuero AG. Cyclodextrins: past and present. In: Arora P, Dhingra N, editors. Cyclodextrin - A Versatile Ingred. Rijeka: InTech; (2018). p.3-43 https://doi.org/10.5772/intechopen.72736

[19] Loftsson T, Brewster ME. Pharmaceutical applications of cyclodextrins: basic science and product development. J Pharm Pharmacol. (2010); 62(11): 1607-1621.

https://doi.org/10.1111/j.2042-7158.2010.01030.x

[20] Jambhekar SS, Breen P. Cyclodextrins in pharmaceutical formulations II: Solubilization, binding constant, and complexation efficiency. Drug Discov Today. (2016); 21(2): 363-368. https://doi.org/10.1016/j.drudis.2015.11.016

[21] Ogawa N, Takahashi C, Yamamoto H, Physicochemical characterization of cyclodextrin-drug interactions in the solid state and the effect of water on these interactions. J Pharm Sci. (2015); 104 (3): $942-954$ https://doi.org/10.1002/jps.24319

22] Liu Y, Wang K, Thermodynamics of resulting complexes between cyclodextrins and bile salts. In: Morales-Rondriguez R, editor. Thermodynamics - Fundamentals and Its Application in Science. Rijeka: InTech; (2012). p. 305-318. ISBN:978-953-51-0779-8

[23] Cirri M, Mennini N, Maestrelli F, Mura P, Ghelardini C, di Cesare Mannelli L. Development and in vivo evaluation of an innovative "hydrochlorothiazide-in cyclodextrins-in solid lipid nanoparticles" formulation with sustained release and enhanced oral bioavailability for potential hypertension treatment in pediatrics. Int $J$ Pharm. (2017); 521(1-2): 73-83 https://doi.org/10.1016/j.ijpharm.2017.02.022

[24] Hou X, Zhang W, He M, Lu Y, Lou K, Gao F. Preparation and characterization of $\beta$-cyclodextrin grafted $\mathrm{N}$-maleoyl chitosan nanoparticles for drug delivery. Asian J Pharm Sci. (2017); 12(6): 558-568. https://doi.org/10.1016/j.ajps.2017.07.007

[25] Sabadini E, Cosgrove T, do Carmo Egídio F. Solubility of cyclomaltooligosaccharides (cyclodextrins) in $\mathrm{H} 2 \mathrm{O}$ and $\mathrm{D} 2 \mathrm{O}$ : a comparative study. Carbohydr Res. (2006); 341(2): 270-274. https://doi.org/10.1016/j.carres.2005.11.004

[26] Jansook P, Ogawa N, Loftsson T. Cyclodextrins: structure, physicochemical properties and pharmaceutical applications. Int $J$ Pharm. (2018); 535(1-2): 272-284. https://doi.org/10.1016/j.ijpharm.2017.11.018

[27] Jantarat C, Sirathanarun P, Ratanapongsai S, Sunyapong S, Wadu A. Curcumin-hydroxypropyl- $\beta$-cyclodextrin inclusion complex preparation methods: effect of common solvent evaporation, freeze drying, and $\mathrm{pH}$ shift on solubility and stability of curcumin. Trop $J$ Pharm Res. (2014); 13(8): 1215-1223. https://doi.org/10.4314/tjpr.v13i8.4

[28] Ghosh A, Biswas S, Ghosh T. Preparation and evaluation of silymarin $\beta$-cyclodextrin molecular inclusion complexes. J Young Pharm. (2011); 3(3): 205-210 https://doi.org/10.4103/0975-1483.83759

[29] George SJ, Vasudevan DT. Studies on the Preparation, characterization, and solubility of $2-\mathrm{HP}-\beta$-cyclodextrin-meclizine $\mathrm{HCI}$ inclusion complexes. J Young Pharm. (2012); 4(4): 220-227. https:// doi.org/10.4103/0975-1483.104365

[30] Loh GOK, Tan YTF, Peh KK. Enhancement of norfloxacin solubility via inclusion complexation with $\beta$-cyclodextrin and its derivative hydroxypropyl- $\beta$-cyclodextrin. Asian J Pharm Sci. (2016); 11(4): 536-546. https://doi.org/10.1016/j.ajps.2016.02.009

[31] Sauceau M, Rodier E, Fages J. Preparation of inclusion complex of piroxicam with cyclodextrin by using supercritical carbon dioxide. $\mathrm{J}$ Supercrit Fluids. (2008); 47(2): 326-332. https://doi.org/10.1016/j.supflu.2008.07.006

[32] Zhou X, Liang JF. A fluorescence spectroscopy approach for fast determination of $\beta$-cyclodextrin-guest binding constants. $J$ Photochem Photobiol A: Chem. (2017); 349: 124-128. https://doi.org/10.1016/j.jphotochem.2017.09.032 
[33] Higuchi T, Connors KA. Phase-solubility techniques. In: Reilley CN, editor. Advances in Analytical Chemistry and Instrumentation: Volume 4. Haboken: Jonh Wiley \& Sons; (1965). p. 117-212.

[34] Zhao R, Sandström C, Zhang H, Tan T. NMR Study on the Inclusion Complexes of $\beta$-Cyclodextrin with Isoflavones. Molecules. (2016); 21 (4): 372.

https://doi.org/10.3390/molecules21040372

[35] Prestinaci F, Pezzotti P, Pantosti A. Antimicrobial resistance: a globa multifaceted phenomenon. Pathog Glob Health. (2015); 109(7): 309318 https://doi.org/10.1179/2047773215Y.0000000030

[36] Wiederhold N, Antifungal resistance: current trends and future strategies to combat. Infect Drug Resist. (2017); 10: 249-259. https://doi.org/10.2147/IDR.S124918

[37] Siafaka PI, Zisi AP, Exindari MK, Karantas ID, Bikiaris DN. Porous dressings of modified chitosan with poly(2-hydroxyethyl acrylate) for topical wound delivery of levofloxacin. Carbohydr Polym. (2016); 143(5): 90-99. https://doi.org/10.1016/j.carbpol.2016.02.009

[38] Paczkowska M, Szymanowska-Powałowska D, Mizera M, Siąkowska D, Błaszczak W, Piotrowska-Kempisty H, Cielecka-Piontek J Cyclodextrins as multifunctional excipients: influence of inclusion into $\beta$-cyclodextrin on physicochemical and biological properties of tebipenem pivoxil. PLoS One. (2019); 14(1): e0210694. https://doi.org/10.1371/journal.pone.0210694

[39] Jelić R, Tomović M, Stojanović S, Joksović L, Jakovljević I, Djurdjević P. Study of inclusion complex of $\beta$-cyclodextrin and levofloxacin and its effect on the solution equilibria between gadolinium(III) ion and levofloxacin. Monatshefte Für Chemie Chem Mon. (2015); 146: 1621-1630. https://doi.org/10.1007/s00706-015-1482-Z

[40] Sanbhal N, Saitaer X, Li Y, Mao Y, Zou T, Sun G, Wang L. Controlled levofloxacin release and antibacterial properties of $\beta$ cyclodextrins-grafted polypropylene mesh devices for hernia repair. Polymers. (2018); 10(5): 493. https://doi.org/10.3390/polym10050493

[41] Aytac Z, Yildiz ZI, Kayaci-Senirmak F, Tekinay T, Uyar T. Electrospinning of cyclodextrin/linalool-inclusion complex nanofibers: Fast-dissolving nanofibrous web with prolonged release and antibacterial activity. Food Chem. (2017); 231: 192-201. https://doi.org/10.1016/j.foodchem.2017.03.113

[42] Szabó ZI, Deme R, Mucsi Z, Rusu A, Mare AD, Fiser B, Toma F, Sipos E, Tóth G. Equilibrium, structural and antibacterial characterization of moxifloxacin- $\beta$-cyclodextrin complex. $J \mathrm{Mo}$ Struct. (2018); 1166: 228-236. https://doi.org/10.1016/j.molstruc.2018.04.045

[43] Masood F, Yasin T, Bukhari H, Mujahid M. Characterization and application of roxithromycin loaded cyclodextrin based nanoparticles for treatment of multidrug resistant bacteria. Mater Sci Eng: C. (2016); 61: 1-7.

https://doi.org/10.1016/j.msec.2015.11.076

[44] He D, Deng P, Yang L, Tan Q, Liu J, Yang M, Zhang J. Molecular encapsulation of rifampicin as an inclusion complex of hydroxypropyl - $\beta$-cyclodextrin: Design; characterization and in vitro dissolution. Colloids Surfaces B Biointerfaces. (2013); 103: 580-585. https://doi.org/10.1016/j.colsurfb.2012.10.062

[45] Choi JM, Park K, Lee B, Jeong D, Dindulkar SD, Choi Y, Cho E, Park S, Yu J, Jung S. Solubility and bioavailability enhancement of ciprofloxacin by induced oval-shaped mono-6-deoxy-6aminoethylamino- $\beta$-cyclodextrin. Carbohydr Polym. (2017); 163 118-128. https://doi.org/10.1016/j.carbpol.2017.01.073

[46] Taha M, Chai F, Blanchemain N, Neut C, Goube M, Maton M, Martel B, Hildebrand HF. Evaluation of sorption capacity of antibiotics and antibacterial properties of a cyclodextrin-polymer functionalized hydroxyapatite-coated titanium hip prosthesis. Int J Pharm. (2014); 477(1-2): 380-389.

https://doi.org/10.1016/j.ijpharm.2014.10.026

[47] Li J, Zhang S, Zhou Y, Guan S, Zhang L. Inclusion complexes of fluconazole with $\beta$-cyclodextrin and 2-hydroxypropyl- $\beta$-cyclodextrin in aqueous solution: preparation, characterization and a structural insight. J Incl Phenom Macrocycl Chem. (2016); 84: 209-217. https://doi.org/10.1007/s10847-016-0598-z

[48] Orgován G, Kelemen H, Noszál B. Protonation and $\beta$-cyclodextrin complex formation equilibria of fluconazole. $J$ Incl Phenom Macrocycl Chem. (2016); 84: 189-196. https://doi.org/10.1007/s10847-016-0595-2

[49] Kim SH, Kwon JC, Park C, Han S, Yim DS, Choi JK, Cho SY, Lee HJ, Park SH, Choi SM, Choi JH, Yoo JH, Lee DG, Lee JW, Therapeutic drug monitoring and safety of intravenous voriconazole formulated with sulfobutylether $\beta$-cyclodextrin in haematological patients with renal impairment. Mycoses. (2016); 59(10): 644-651. https://doi.org/10.1111/myc.12517
50] Yasu T, Konuma T, Kuroda S, Takahashi S, Tojo A. Effect of cumulative intravenous voriconazole dose on renal function in hematological patients. Antimicrob Agents Chemother. (2018); 62(9): $1-4$ https://doi.org/10.1128/AAC.00507-18

[51] Sun X, Yu Z, Cai Z, Yu L, Lv Y. Voriconazole composited polyvinyl alcohol/hydroxypropyl- $\beta$-cyclodextrin nanofibers for ophthalmic delivery. PLoS One. (2016); 11(12): e0167961. https://doi.org/10.1371/journal.pone.0167961

[52] Vass P, Démuth B, Farkas A, Hirsch E, Szabó E, Nagy B, Andersen SK, Vigh T, Verreck G, Csontos I, Marosi G, Nagy ZK. Continuous alternative to freeze drying: Manufacturing of cyclodextrin-based reconstitution powder from aqueous solution using scaled-up electrospinning. J Control Release. (2019); 298: 120-127. https://doi.org/10.1016/j.jconrel.2019.02.019

[53] Herrera A, Rodríguez FJ, Bruna JE, Abarca RL, Galotto MJ, Guarda A, Mascayano C, Sandoval-Yáñez C, Padula M, Felipe FRS Antifungal and physicochemical properties of inclusion complexes based on $\beta$-cyclodextrin and essential oil derivatives. Food Res Int. (2019); 121: 127-135. https://doi.org/10.1016/j.foodres.2019.03.026

[54] Jansook P, Prajapati M, Pruksakorn P, Loftsson T. Antifungal activity of econazole nitrate/cyclodextrin complex: Effect of $\mathrm{pH}$ and formation of complex aggregates. Int J Pharm. (2020); 574: 118896. https://doi.org/10.1016/j.ijpharm.2019.118896

[55] Eleamen GRA, da Costa SC, Lima-Neto RG, Neves RP, Rolim LA, Rolim-Neto PJ, Moura RO, de Aquino TM, Bento ES, Scotti MT, Mendonça-Junior FJB, Mendonça EAM, Oliveira EE. Improvement of solubility and antifungal activity of a new aminothiophene derivative by complexation with 2 -hydroxypropyl- $\beta$-cyclodextrin. $J$ Braz Chem Soc. (2016); 28(1) 116-125.

https://doi.org/10.5935/0103-5053.20160153

[56] Gontijo AV, da G Sampaio A, Koga-Ito CY, Salvador MJ. Biopharmaceutical and antifungal properties of ellagic acidcyclodextrin using an in vitro model of invasive candidiasis. Future Microbiol. (2019); 14(11): 957-967. https://doi.org/10.2217/fmb-2019-0107

[57] Minea B, Marangoci N, Peptanariu D, Rosca I, Nastasa V, Corciova A, Varganici C, Nicolescu A, Fifere A, Neamtu A, Mares M, Barboiu $\mathrm{M}$, Pinteala $\mathrm{M}$. Inclusion complexes of propiconazole nitrate with substituted $\beta$-cyclodextrins: the synthesis and in silico and in vitro assessment of their antifungal properties. New J Chem. (2016); 40(2): $1765-1776$ https://doi.org/10.1039/C5NJ01811K

[58] Teodoro GR, Gontijo AVL, Borges AC, Tanaka MH, de Morais Gouvêa Lima G, Salvador MJ, Koga-Ito CY, Gallic acid/ hydroxypropyl- $\beta$-cyclodextrin complex: Improving solubility for application on in vitro/ in vivo Candida albicans biofilms. PLoS One. (2017); 12(7) e0181199. https://doi.org/10.1371/journal.pone.0181199

[59] Saokham P, Muankaew C, Jansook P, Loftsson T. Solubility of cyclodextrins and drug/cyclodextrin complexes. Molecules. (2018) 23(5): 1-15.

https://doi.org/10.3390/molecules23051161

[60] Jambhekar SS, Breen P. Cyclodextrins in pharmaceutical formulations I: Structure and physicochemical properties, formation of complexes, and types of complex. Drug Discov Today. (2016); 21(2): 356-362.

https://doi.org/10.1016/j.drudis.2015.11.017

[61] dos Passos Menezes P, de Araújo Andrade T, Frank LA, de Souza EPBSS, das Graças Gomes Trindade G, Trindade IAS, Serafini MR, Guterres SS, de Souza Araújo AA. Advances of nanosystems containing cyclodextrins and their applications in pharmaceuticals. Int J Pharm. (2019); 559: 312-328. https://doi.org/10.1016/j.ijpharm.2019.01.041

62] Tian B, Hua S, Liu J. Cyclodextrin-based delivery systems for chemotherapeutic anticancer drugs: A review. Carbohydr Polym. (2020); 232: 115805 https://doi.org/10.1016/j.carbpol.2019.115805

[63] Shahiwala A. Cyclodextrin conjugates for colon drug delivery. J Drug Deliv Sci Technol. (2020); 55: 101448. https://doi.org/10.1016/j.jddst.2019.101448

[64] Chaudhari P, Ghate VM, Lewis SA. Supramolecular cyclodextrin complex: Diversity, safety, and applications in o cular therapeutics. Exp Eye Res. (2019); 189: 107829. https://doi.org/10.1016/j.exer.2019.107829

65] Radu CD, Parteni O, Ochiuz L. Applications of cyclodextrins in medical textiles - review. J Control Release. (2016); 224: 146-157. https://doi.org/10.1016/j.jconrel.2015.12.046 